\title{
La Pequeña Habana miamense o la metáfora del anticastrismo y de la cubanidad: lectura sicocrítica de El año que viene estamos en Cuba de Gustavo Pérez Firmat
}

\author{
Georges Moukouti Onguédou \\ Universidad de Maroua (Camerún) \\ moukouti@yahoo.fr
}

ResUM

La Petita Havana o "Little Havana" és un espai mític i real alhora, ubicat a Miami, Florida. Representa l'epicentre de la vida social, cultural i fins i tot política de la comunitat cubana de l'exili nord-americà. En la crònica autobiogràfica El año que viene estamos en Cuba (1997), es revela com a metàfora de l'anticastrisme o alegorización inconfessada de la ideologia anticomunista, a la vegada transplantament de la cubanitat. Gustavo Pérez Firmat, autor de l'obra, considera La Petita Havana com a succedani de l'Havana de Cuba on ell es queda immune "contra el virus de l'assimilació" i on ningú es sorprèn del seu anticastrisme. Partint dels plantejaments teòrics de la Sicocrítica de Charles Mauron (1963), destaquem d'aquesta actitud fets i relacions inherents a la personalitat inconscient de l'autor.

Paraules clau

La Petita Havana, Fidel Castro, anticastrisme, cubanitat, metàfora.

\section{RESUMEN}

La Pequeña Habana o "Little Havana” es un espacio mítico y real a la vez, ubicado en Miami, Florida. Representa el epicentro de la vida social, cultural y hasta política de la comunidad cubana del exilio estadounidense. En la crónica autobiográfica El año que viene estamos en Cuba (1997), se revela como metáfora del anticastrismo o alegorización inconfesada de la ideología anticomunista, a la par trasplantación de la cubanidad. Gustavo Pérez Firmat, autor de la obra, considera La Pequeña Habana como sucedáneo de La Habana de Cuba donde él se queda inmune "contra el virus de la asimilación" y donde nadie se sorprende de su anticastrismo. Partiendo de los planteamientos teóricos de la Sicocrítica de Charles Mauron (1963), destacamos de esta actitud hechos y relaciones inherentes a la personalidad inconsciente del autor.

\section{Palabras clave}

La Pequeña Habana, Fidel Castro, anticastrismo, cubanidad, metáfora.

\section{RÉSUMÉ}

La Petite Havane ou "Little Havana" est un espace à la fois mythique et réel, situé à Miami en Floride. Il représente l'épicentre de la vie sociale, culturelle y même politique de la communauté cubaine en exil aux Etats-Unis. Dans la chronique autobiographique El año que viene estamos en 
Cuba (1997), cet espace se révèle comme métaphore de l'anticastrisme ou allégorisation inavouée de l'idéologie anticommuniste, et en même temps comme transplantation de la cubanité. Gustavo Pérez Firmat, auteur de l'œuvre, considère La Petite Havane comme succédané de La Havane du Cuba où il reste immunisé contre le virus de l'assimilation et où personne ne se surprend de son anticastrisme. Partant de la théorie psychocritique de Charles Mauron (1963), il ressort de cette attitude des faits et relations inhérents à la personnalité inconsciente de l'auteur.

MOTS- CLÉ

La Petite Havane, Fidel Castro, anticastrisme, cubanité, métaphore.

\section{Abstract}

The Little Havana is both a mythical and real space, located in Miami, Florida. It represents the epicenter of the social, cultural and even political life of the Cuban community living in exile in the United States. In the autobiographical chronicle El año que viene estamos en Cuba (1997), this space appears like a metaphor of the anticastrism or an unavowed allegorization of the anticommunist ideology. It is also seen like a transplantation of cubanity. Gustavo Pérez Firmat, author of the book, considers The Little Havana as a substitute for Havana of Cuba, where he remains immune to the virus of assimilation and where no one is surprised by his anticastrism. Analyzed from Charles Mauron's Psychocriticism theory (1963), this attitude reveals facts and relations inherent in the author's unconscious personality.

\section{KEYWORDS}

The Little Havana, Fidel Castro, anticastrism, cubanity, metaphor.

\section{Introducción}

¡El año que viene estamos en Cuba! Con esta frase a la vez título de la obra del escritor cubanoestadounidense Gustavo Pérez Firmat (1997), los disidentes cubanos exiliados en Miami tras el triunfo de la Revolución castrista celebraban la Navidad y el Año Nuevo. Con un brindis, se convencían de que prontamente regresarían a Cuba, porque para ellos, el fracaso de la Revolución y la caída de Castro eran inminentes. Movidos por el sentimiento de pertenencia a un mismo pueblo $^{1}$, estos disidentes cubanos del régimen castrista crean en Miami, entre los años sesenta y setenta, la Pequeña Habana o "Little Habana", un espacio mítico y real a la vez, sucedáneo de La Habana de Cuba, epicentro de la vida social, cultural y hasta política de la comunidad cubana exiliada. Este espacio ha terminado generando temas como el anticastrismo y la cubanidad. Algunas reflexiones, además de las diferentes antologías sobre la literatura cubano-estadounidense, versan sobre estas preocupaciones. Nos referimos a los ensayos The Cuban Condition: Translation and Identity in Modern Cuban Literature (1989), My own private Cuba. Essays on Cuban Literature and Culture (1999), Vidas en vilo. La cultura cubanoamericana (2000b) y Cincuenta lecciones de 
exilio y desexilio (2000a) del propio Gustavo Pérez Firmat, donde los temas del anticastrismo, de la cubanidad, de la cubanía, de lo cubano y del cubaneo vienen bastante referenciados. Fernando Ortiz, en su famoso ensayo "Los factores humanos de la cubanidad" (1940), trata de la cubanidad y de la cubanía y analiza la metáfora del ajiaco como síntesis y símbolo de la cubanía (se compara a Cuba a un ajiaco, y eso se aplica también para la Cuba del norte representada por la Pequeña Habana miamense). Entiende la cubanidad como la calidad de lo cubano y considera que Cuba es tanto tierra como pueblo. Y el pueblo cubano se extiende allende los mares, como parece afirmarlo el cubano Reinaldo Arenas quien, en su carta de despedida (antes de suicidarse en el exilio), se dirige al "pueblo cubano tanto en el exilio como en la Isla" (2000), en su lucha por la libertad. Con Carlos Ferrer Peńaranda en su artículo "Castrismo y anticastrismo en la red: análisis ideológico de los comentarios a la muerte de Laura Pollán en el periódico digital Público.es” (2012), se examina, desde una perspectiva ideológica, las reacciones que suscitó en España en un foro de discusión la muerte de la disidente cubana Laura Pollán. El análisis de estas reacciones da una predominancia de las opiniones anticastristas sobre las castristas. En un artículo periodístico titulado "Breve historia del anticastrismo en Miami"2, Michael Moore, tras pasar revista a las relaciones frías entre Estados Unidos y Cuba, culpa a muchos cubanos de Miami, "acólitos de Batista", de nutrir la animadversión entre estos dos países a causa de su anticastrismo. Ironizando, ve en Fidel Castro alguien que sobrevivió a ocho presidentes estadounidenses, alguien que con el tiempo, a pesar de los varios embargos y agresiones contra él y contra Cuba, se volvió más fuerte mientras que Estados Unidos iba pasando vergüenza.

La autobiografía El año que viene estamos en Cuba refleja la condición de Gustavo Pérez Firmat y de otros cubanos exiliados como él que sueñan en cubanos $^{3}$ y al mismo tiempo manifiestan su resentimiento contra Fidel Castro. Eso nos lleva a plantearnos desde luego la pregunta de si la Pequeña Habana no se habrá convertido en metáfora a la vez del anticastrismo y de la cubanidad. Se trata, por lo tanto, de analizar la Pequeña Habana como una alegorización inconfesada de la ideología anticomunista y anticastrista del bastión cubano exiliado; y de considerar también que este espacio representa la cubanidad trasplantada. Para llevar a cabo este opúsculo, nos valemos de los planteamientos teóricos de la Sicocrítica de Charles Mauron (1963), explorando los hechos y las relaciones inherentes a la personalidad inconsciente del autor; los cuales revelan La Pequeña Habana miamense como metáfora del anticastrismo y de la cubanidad. El artículo no pretende observar al pie de la letra los lineamientos teóricos del método sicocrítico que tradicionalmente consisten en analizar las redes de obsesiones temáticas del autor en su producción artística. Esta tarea también se puede hacer en un solo texto del autor, pues la Sicocrítica consiste asimismo en estudiar un texto para destacar los hechos y las relaciones inherentes a la personalidad inconsciente del escritor o del personaje. Vamos a ver si las redes de asociaciones inconscientes (abstractas por lo general) articuladas en torno a los ejes temáticos del anticastrismo y de la cubanidad nos permitirán entender la significación de la obra a partir de la personalidad inconsciente de su autor. La sicocrítica nos ayudará precisamente a sacarnos de dudas porque su propósito descansa en el descubrimiento de las motivaciones psicológicas inconscientes del individuo por medio de sus propios escritos y propósitos.

2. Disponible en http://cartasdesdecuba.com/breve-historia-del-anticastrismo-de-miami/. Consultado el 10 de mayo de 2017.

3. Tomamos prestada esta expresión de la cubano-estadounidense Cristina García en su obra Soñar en cubano publicada en español en Madrid, Espasa Calpe, 1998. 


\section{Redes de asociaciones mnemotécnicas y construcción del mito personal en torno al anticastrismo}

Las diferentes metáforas obsesionantes o redes de asociaciones inconscientes son asociaciones de ideas inconscientes que se repiten igual o casi a lo largo de la obra de un escritor. Pueden ser también —así se maneja usualmente el método sicocrítico — ideas que se repiten durante un periodo de la producción artística del escritor, o ideas que sufren variaciones significativas. Permiten desentrañar el mito personal gracias al cual el escritor traduce los conflictos que constituyen finalmente su verdadera personalidad. Partiendo de los fundamentos teóricos de Charles Mauron, toda obra de arte como es Elaño que viene estamos en Cuba surge del debate entre el Yo inconsciente del escritor, su Yo consciente y el lugar en que este escritor debe adaptarse. Asistimos en esta crónica autobiográfica a una superposición de textos que metaforizan las redes asociativas y las imágenes obsesivas de Gustavo Pérez Firmat y que, consecuentemente, revelan el anticastrismo del autor. Estas redes e imágenes que refuerzan la memoria aparecen repetidas veces en esta obra del autor (y también en otra de su producción literaria que abarca poesía, novela y ensayo), constituyendo precisamente lo que Charles Mauron llama "mito personal", o sea, la manifestación de la personalidad inconsciente del autor. El inconsciente de Pérez Firmat — que no significa estado de no conciencia— se manifiesta por ejemplo a la hora de describir lo que representa la Pequeña Habana miamense para él:

Miami me brinda algo que no encuentro en ningún otro sitio — la sensación de pertenencia, de formar parte de una colectividad. En Cuba la cerveza Cristal se anunciaba con la frase, '¿Hay ambiente, mi gente?' Eso es Miami para mí — gente y ambiente. Hombres y mujeres que sienten y hablan como yo, que no se sorprenden de mi anticastrismo y no se asustan al ver dos tabacos en el bolsillo de la camisa. En Miami no tengo que deletrear mi nombre, ni explicar mis chistes, ni disimular mis sentimientos (1997: 65).

El recurso reiterativo a la primera persona del singular (me, mi, mí, yo, mis) se revela ser la expresión de los pensamientos del autor, pero más aún de sus sentimientos. En realidad, en Miami tiene la ventaja de no poder disimular sus sentimientos, y en este caso su anticastrismo. Luego, cuando confrontamos las modalidades del "Yo" en esta obra con sus datos biográficos y con las alusiones a su "gente", "hombres y mujeres que sienten y hablan" como el propio Yo, o sea la "colectividad" a la que forma parte, desembocamos en la historia no sólo de la personalidad del propio escritor, sino además en la historia colectiva de los exiliados cubanos en Miami durante la era castrista. El anticastrismo del Yo, de su familia y de la gente que desde luego constituyen esta colectividad cubana del exilio en Miami ya se evidencia tras el triunfo de la Revolución en 1959.

Desde entonces, la familia Pérez Firmat, pro-batista, expuso su resentimiento contra la Revolución. Mientras miles de cubanos se echaban a la calle para darle la bienvenida a Castro y que otros le decía: "Fidel, ésta es tu casa", el ambiente fue diferente en casa de Pérez Firmat: "no fue así en mi casa, donde cualquier cosa que tuviera que ver con la Revolución estaba terminantemente prohibida. Desde el primer momento, nos consideramos 'gusanos', el apelativo con el cual Fidel Castro estigmatizó a sus enemigos” (1997: 11). Durante su exilio en Miami, este resentimiento se fue aumentando. En un bar, mientras se tomaba un trago, el padre de Gustavo exclamó: "-Me cago en Fidel, me cago en la Revolución, me cago en la suerte, me cago en la mismísima mierda” (1997: 78). El sentido de este verbo discrepa, desde luego, con el del español, donde se caga en la leche, en su padre, en su madre e incluso en Dios. Obviamente, el sentido del verbo "cagarse" 
discrepa un tanto del que destaca de las anécdotas y de los chistes en la cultura española. Para Octavio Paz (2007: 89) "los españoles se complacen en la blasfemia y la escatología [...]. El español es simple: insulta a Dios porque cree en él. La blasfemia, dice Machado, es una oración al revés”.Al contrario, el uso (repetitivo) del verbo "cagarse" en esta obra convoca la maldición de Pérez Firmat contra todo lo que tiene que ver con Castro y el Castrismo.

Por otra parte, el Yo y la colectividad cubana de Miami estaban constantemente pegados a la radio y a la televisión, en espera de noticias que les anunciara el fin del régimen castrista. En efecto,

no hay exiliado cubano que, alguna vez, no haya recibido una llamada de un amigo diciéndole, en una voz empapada de emoción, 'Chuco, jse cayó Fidel!' [...] Cuando la llamaba con la bola de que había ocurrido un atentado en Cuba, en media hora alguien llamaba a casa con la noticia de que Fidel estaba muerto. [...] Las noticias de Cuba eran alimento y narcótico — nos llenaban de embullo, calmaban nuestras ansiedades y nuestro desespero— pero a la vez nos adormecían (1997: 53).

Asistimos, esta vez, al recurso a la primera persona del plural (nos, nuestras y nuestros). El "nosotros" (yo + tú o yo + él / ella), susceptible de varias extensiones, puede implicar la existencia de un "ellos" o de un "vosotros" diferentes de "nosotros" (Cros, 1982: 232). En cualquier caso las marcas del "Yo" y del "Nosotros" evidenciarían aquí la postura ideológica de Gustavo Pérez Firmat y otros cubanos exiliados en Miami, anticastristas por lo general, frente a los castristas; aunque también servirían para plantear el problema de la identidad y de la pertenencia a un grupo que se siente al margen.Por sentirse precisamente al margen, estos cubanos brindaban cada vez que les surgía un resquicio de esperanza respecto de un inminente derrocamiento del régimen castrista o de una supuesta muerte de Castro con la frase “¡El año que viene estamos en Cuba!”. En los primeros años "cuando la dictadura castrista estaba sólidamente afianzada en el poder", los cubanos exiliados seguían "pensando en el regreso, pero sin grandes esperanzas"; aun cuando "los presidentes norteamericanos iban y venían, los dictadores hispanoamericanos subían y bajaban", "Fidel seguía en el poder". Pero con la desaparición de la Unión Soviética que le brindaba apoyo a Castro, los cubanos de Miami se convencieron de que "nuestro largo exilio está llegando a su fin" (1997: iv-v); de ahí, esta frase que metaforiza el obsesionante sentimiento anticastrista de los exiliados cubanos en Miami y que, epónima y metonímicamente resume la obra.

Cuando estalló la Guerra de Vietnam, se incorporaron muchos cubanos para combatir, con la esperanza de que correlativamente su acción afectara la política estadounidense hacia Cuba. Gustavo Pérez Firmat no se apuntó, porque pensó: “¿por qué cruzar medio mundo para detener el comunismo cuándo [sic] se podía combatir a noventa millas? Yo no tenía ningún deseo de que me llevaran para Vietnam, pero sí me apunté en Alpha 66, una organización de exiliados que llevaba a cabo ataques contra el régimen de Castro" (1997: 51). Pero, al carecer de entrenamiento militar, confiesa no haber llegado a participar en Alpha 66.

Además de este sentimiento anticomunista que pretende desprestigiar todo aquello que tenga relación con el Comunismo sustentador del Castrismo, otra manifestación del anticastrismo de los cubanos de La Pequeña Habana miamense surge de las actividades políticas de José Francisco Alabau, ex juez del Tribunal Supremo de Justicia tras el triunfo de la Revolución (exiliado luego en Miami), y que Pérez Firmat presenta como un profeta cuyas palabras parecían redentoras. Y es que Pérez Firmat alaba a Alabau como fundador del Movimiento Unitario Invasor. De él "se rumoraba que contaba con el apoyo del Presidente Nixon. La meta del Movimiento Cubano Invasor era infiltrarse en Cuba y establecer un gobierno provisional, con la expectativa de que Estados Unidos 
lo reconociera y le prestara apoyo" (1997: 54). Mas tras una incursión infructuosa en la costa sur de la provincia de Camagüey, Alabau anunció en Radio La Pequeńa Habana que el Movimiento dio una batalla que concluyó con la muerte de más de cincuenta soldados comunistas. Sus palabras conclusivas a modo de exhortación a todo el pueblo cubano fueron: "—iEstamos a punto de despertar de nuestra larga pesadilla histórica! ¡Con esta hazaña heroica ha comenzado la fase final de la guerra contra el tirano! ¡Ha llegado el momento para que todos los cubanos, aquí y en la isla, nos unamos a esta gloriosa empresa!" (1997: 55). De lo que surge de estas palabras, podemos considerar La Pequeña Habana miamense como alegoría de la lucha anticastrista de los disidentes cubanos en el exilio. La proximidad geográfica de Miami con la isla (noventa millas de distancia) hace de este espacio un paradero predilecto para los exiliados cubanos - burguesía blanca por lo generaldándoles la impresión de estar finalmente en casa. Además, en tiempos de Fidel Castro, Pérez Firmat y demás cubanos exiliados sabían que el vecino norteamericano le tenía gran animosidad contra la Revolución castrista y el Comunismo; y eso les podía brindar protección y alianza.

\section{Modalidades textuales de la cubanidad en La Pequeńa Habana miamense}

Estas modalidades participan de la (re)construcción de la identidad desde la perspectiva de la cubanidad en Miami, habida cuenta que La Pequeña Habana miamense de la obra reenvía a la diáspora cultural cubana. Recurrir a la Sicocrítica permite, como acabamos de hacerlo con las redes de asociaciones mnemotécnicas y la construcción del mito personal, manejar el texto y las palabras del texto, siendo un método de exploración. La autobiografía también es exploratoria, y recurrir a ella participa, sin dudas algunas, del deseo de Gustavo Pérez Firmat de (re)descubrirse a sí mismo mediante la escritura. Este recurso le permite explorar su pasado y (re)construir, por medio de los cuadros sociales de la memoria (Halbwachs, 1994), su idendidad que podría corresponder con su “cubanidad” en La Pequeña Habana miamense.

Con esta obra, Pérez Firmat alegoriza una visión a la vez histórica y contemporánea de la identidad cubana en el exilio (José Martí o Tomás Estrada Palma — primer presidente de Cuba— vivieron tantos años en el exilio estadounidense, pero no dejaron por tanto, según el autor, de ser cubanos hasta la muerte). Pérez Firmat se autodefine entonces en términos siguientes:

Soy cubano, soy americano. Pertenezco a lo que se ha dado en llamar la generación 'uno-y-medio', o sea, cubanos que nacieron en la isla y llegaron a los Estados Unidos cuando eran niños o adolescentes [...] Después de tantos años en Estados Unidos, me resulta difícil imaginar una vida al margen de la cultura norteamericana y del idioma inglés. Sin embargo, Cuba no deja de ser mi patria, mi lugar más mío, el que más ha moldeado mis creencias y querencias (1997: iii).

A pesar de esta doble pertenencia a Cuba que el autor considera como su hogar y a Estados Unidos, un lugar que eligió su familia para ubicarse, destacamos de estas palabras un marcado grado de cubanidad manifestada, según Ortiz citado por Jorge Castellanos (2003: 137), desde tres ámbitos: "en el arte, en la religión y en el tono de la emotividad colectiva". Y estas tres manifestaciones de la cubanidad se reflejan en Pérez Firmat, al menos en el ámbito artístico y emotivo. Para no perder su cubanidad y permanecer siempre inmune contra la asimilación, no se desconecta por completo de La Pequeña Habana. Incluso tras haberse trasladado a Carolina del Norte por razones profesionales, regresa como otros exiliados cubanos a La Pequeña Habana donde aspira a vivir "varios días de 
cubanía y cubaneo" que le dan "varios meses de inmunidad contra el virus de la asimilación", propinándose así "inyecciones de cubanicilina" (1997: 183).

Su padre, aun después de haber vivido más años en el exilio que en Cuba, a pesar de "ser 'residente permanente' de Estados Unidos [...] seguirá siendo ciudadano eterno de Cuba" (1997: xii). Estas revelaciones testimonian también la doble pertenencia de muchos cubanos a Cuba que Pérez Firmat considera como su patria, su hogar y a Estados Unidos, un país, un lugar. En efecto,

Cuba es mi patria, pero Estados Unidos es mi país. Patria es una palabra rara, ya que combina una raíz masculina (de pater, padre) con una desinencia femenina, como si el suelo que nos vio nacer fuese a la vez madre y padre [...] Siento hacia Cuba el cariño insobornable que se siente hacia un padre o una madre. Siento hacia los Estados Unidos el carińo no menos profundo pero voluntario que se siente hacia un esposo o una esposa. No puedo dejar de querer a Cuba; tal vez podría dejar de querer a los Estados Unidos, como podría dejar de querer a mi mujer (1997: 199).

Hasta su hijo David, nacido en Miami y no en La Habana como su padre, siempre confiesa, cada vez que se le pregunta de dónde es, que él es cubano, aunque expresa su cubanidad, o lo que el propio autor llama "cubanía", hablando en inglés. Si bien es que sus hijos nacieron en Estados Unidos, pudo someterlos "a fuertes dosis de cubanía” (1997: xii). El propio Pérez Firmat no vacila en afirmar orgullosamente su cubanía o cubanidad, y no quiere que lo distraigan con otros apelativos, como cuando lo pueden llamar latino, pues "no me siento 'latino' sino cubano —cubiche, cubanazo, cubanito (sí señores), Cuban” (1997: 63), pese a que es tambiénun cubano híbrido, el cubano del "hyphen", en vilo, en el limbo o "in between",

el vilómanoone-and-a-halfer que se tambalea en la cuerda floja entre lo cubano y lo norteamericano, no ha dejado de ser cubano, aunque sea otra cosa. Del mismo, el escritor cubanoamericano que se entrega a evocar en inglés una vida que no ha vivido, no ha dejado de ser cubano, pero también es otra cosa. [...] El guión de Cuban-American no es un signo de restar sino de sumar, con igual propiedad podríamos llamarnos 'Cuban+American' (Pérez Firmat, 2000b: 27).

Cuando al autor le toca imaginarse que se traicionó a sí mismo escribiendo algunas de sus obras originalmente en inglés, en vez de escribirlas primero en español, considera simplemente que una lengua es un lugar. Al escribir primero en inglés y luego en español, quiere decir: "estoy” en Estados Unidos (ubicación) pero"soy" de Cuba (origen). Pero ante la primera situación, Pérez Firmat confiesa que "entre las muchas razones que un individuo puede tener para desplazarse de la lengua materna a la lengua alterna, una de las más poderosas es el rencor. Escribir en inglés es o puede ser un acto de venganza —contra los padres, contra las patrias, contra uno mismo" (Pérez Firmat, 2000a: 23). Pero, el rencor aparte, admite el autor que "al redactar la versión en inglés, quise convertirme en americano. Al traducirlo al espańol, me siento más cubano que nunca, y sospecho que si lo hubiera escrito primero en español, el libro hubiera salido muy distinto" (1997: 198-199).

La temática que suscita la diáspora cubana en Miami refleja más el apego de los cubanos miamenses a la cultura cubana. Sin embargo, esta cultura, cabe resaltar, es en cierta medida una cultura mestiza, sincrética o híbrida, como es el caso del $\mathrm{Mambo}^{4}$ en tanto expresión musical. El

4. "Concebido en Cuba pero desarrollado fuera de la isla, el mambo también pertenece a la generación del medio, lo cual no quiere decir que haya sido creado por un miembro de esa generación, sino que su hibridez musical lo relaciona 
Yo-protagonista-narrador, símbolo de la identidad colectiva cubano-estadounidense, pertenece a la generación uno y medio, o sea, más de uno y menos de dos, más cubano y menos estadounidense por lo tanto. Su situación en el "hyphen" es la que produce finalmente esta identidad compuesta. Quien oscila entre dos culturas se encuentra a fin de cuentas en conflicto con sí mismo, pues "toda cultura - y muy en particular una cultura desalojada de su ámbito de origen - siempre se ve obligada a conciliar los conflictivos reclamos de la tradición y la traducción" (2000b: 16)5.

De lo que precede, se observa que esta obra de Pérez Firmat constituye una mitología personal, y luego colectiva, rociada de nostalgia, "le plus souvent vécue comme une errance hantée par l'absence" (Olympia, 2005: 52); de ahí, la vida en el "hyphen" o en vilo, o lo que Ilán Stavans (1999) llama la vida en el limbo en la que los cubanos miamenses - incluso de toda la diáspora en el exilio- se sienten como mutilados. Sin embargo, aunque carecen de ubicuidad fija — por ser los exiliados aves sin nido o "aves de paso" (Mertz-Baumgartner y Pfeiffer, 2005)_, esta condición no incurre por tanto en la negación de la esencia o raíz cubana de los exiliados. Más aún, ser anticastrista no implica forzosamente que uno haya dejado de ser cubano. No serían menos cubanos que los nacidos y moldeados en Cuba. La cubanidad, de concierto con Fernando Ortiz,

no la da el engendro, y en ese sentido no hay una raza cubana... La cubanidad para el individuo no está en la sangre, ni en el papel ni en la habitación. La cubanidad es principalmente la peculiar calidad de una cultura, la de Cuba. Dicho en términos corrientes, la cubanidad es condición del alma, es complejo de sentimientos, ideas y actitudes... No basta para la cubanidad integral tener en Cuba la cuna, la nación, la vida y el porte; aún falta la conciencia...; son precisas también la conciencia de ser cubano y la voluntad de querer serlo... Pienso que para nosotros habría de convenir la distinción de la cubanidad, condición genérica de cubano, y la cubanía, cubanidad plena, sentida, consciente y deseada; cubanidad responsable, cubanidad con las tres virtudes — dichas teologales— de fe, esperanza y amor (1991: 13-14).

Con Pérez Firmat y la mayoría de los cubanos de La Pequeña Habana miamense, se puede afirmar que su cubanidad se refleja precisamente en su conciencia y voluntad de permanecer cubanos. Si tomamos el ejemplo del propio Yo-protagonista-narrador, podemos desde luego notar sus constantes esfuerzos contra la asimilación que considera como un virus. Además, el riesgo de contraer este virus no se lo plantea como una alternativa, sino para los que ya se han asimilado. Compara su situación con la de otros cubanos como el escritor neoyorquino Óscar Hijuelos, nacido en Nueva York de padres inmigrantes cubanos, o como José Kozer, nacido en Cuba y exiliado a los Estados Unidos también en 1960, pero que según Pérez Firmat, llegaron al contrario a volverle la espalda a la cultura cubanoamericana. Se supone entonces que el hecho de haber vivido en Miami o de regresar allí de vez en cuando ayuda a Pérez Firmat a vivificar su cubanidad y su amor a la patria. De hecho,

con otras creaciones de esta generación. Igual que la cultura cubanoamericana, el mambo es una música de aceptación y resistencia, que renuncia tanto al regreso como a la asimilación” (Pérez Firmat, 2000b: 24).

5. Según el propio Pérez Firmat (2000b: 16), “la palabra 'tradición' designa convergencia y continuidad, la concurrencia de elementos a partir de afinidades subyacentes o intereses compartidos. En cambio, la 'traducción' no es un mecanismo de convergencia sino de distanciamiento [...] nos enseña que mudar es transmutar, que cualquier traslación lingüística o cultural entraña una alteración del original”. Eso puede explicar concretamente el hecho de que un cubano de Cuba no pueda reflejar las mismas características idiosincráticas de cubanidad que el cubano trasladado; de ahí que el autor distinga claramente la cultura cubano-estadounidense (que después de 1960 ha adquirido características propias), de la cultura cubana de la isla y de la norteamericana (18). 
reconoce que "si no hubiéramos residido en Miami, mi asimilación a la vida norteamericana quizás hubiera continuado sin interrupción, y hoy día no sería yo quien estuviera traduciendo este libro al español" (1997: 37). En consecuencia, el recurso a la lengua materna (el español) para devolverle a su obra sus raíces culturales le permite mantener su identidad lenguajera cubana. Parece, pues, que el hecho de haberse resuelto a escribir más desde y no hacia el español participa de su voluntad de no cambiar de vida, como bien parafrasea él mismo al poeta Derek Walcott quien piensa que "para cambiar de idioma es preciso cambiar de vida" (Pérez Firmat, 2000a: 17).

La cubanidad de los exiliados cubanos en La Pequeña Habana se nutre con el proceso de relocalización y sustitución: se busca "recrear en el destierro a su país de origen", con simulacros en términos "El mismo de Cuba", "Aquí desde el 1953" (Pérez Firmat, 2000b: 19) y afirmaciones "contra viento y marrea" de "la posesión de su país de origen: mi pueblo, mis palmas, mi tierra - como si hubiera tal cosa como un exilio sin destierro. Es por ello que en La Pequeña Habana a veces parece que el tiempo se ha detenido" (Pérez Firmat, 2000b: 20). Se trata de una alternativa para relocalizarse cubanizando un espacio que, desde la dinámica de la mitificación, participa de la sustitución: La Habana por La Pequeña Habana. Como bien dice Celedonio González citado por Nicolás Kanellos, "Cuba se había mudado y lo había traído todo consigo" y "se fue acelerando la cubanización del ambiente a ojos vista” (2002: 491). Este proceso de cubanización continúa luego en la propia casa del autor después de trasladarse a Carolina del Norte. Porque según él el exiliado vive de sustituciones y sucedáneos, termina cubanizando una de sus habitaciones; una manera de (re)encontrarse con Cuba cada vez que entra allí.

\section{Conclusiones}

En palabras esenciales, este artículo que hemos enfocado desde la perspectiva sicocrítica es un análisis de la crónica autobiográfica El año que viene estamos en Cuba del cubano-estadounidense Gustavo Pérez Firmat. Partimos de los hechos y de las relaciones inherentes a la personalidad inconsciente del autor para descubrir y explorar La Pequeña Habana miamense como metáfora del anticastrismo y de la cubanidad. El mito de la personalidad, por medio de los fantasmas, las experiencias traumáticas del régimen castrista, las vehementes tentaciones de regreso a la tierra natal, los recuerdos y recordatorios, etc. exponen al autor como un ser procesado y, desde luego, "condamné à une identité incertaine" (Abastrado, 1979: 11). Todo lo relacionado con el mito personal permite entender la condición de cubano del propio autor y de su cubanidad como rasgo de etnicidad en Miami. La historia de Pérez Firmat es también la historia colectiva de muchos exiliados cubanos, una historia empapada de anticastrismo como reacción contra la ideología castrista. Él mismo reconoce haberse convertido, como otros cubanos más en Estados Unidos, en fanáticos "de extrema derecha cuyo ferviente anticastrismo no es más que una molesta reliquia de la Guerra Fría" y vistos últimamente "como un estorbo a la normalización de relaciones con el régimen de Fidel Castro" (2000a:13).

La crónica autobiográfica de Pérez Firmat — como la mayoría de su producción literaria que abarca poesía, ensayos y novelas - rebosa de metáforas que revelan a la vez su anticastrismo y su cubanidad. Por una parte, el autor recurre obsesionantemente a términos como exilio, refugio, rencor, mala Revolución, vergüenza, mareos, depresión, gusanos, etc. Su familia y demás exiliados (no inmigrantes) constantemente querían saber cuánto tiempo duraría Fidel Castro en el poder o lo que Washington iba a hacer para derrocarlo y poner fin a su régimen. Ya tras el triunfo de la 
Revolución, la familia Pérez Firmat había tomado distancias con Fidel Castro: "el ambiente en casa era como luto, [...] No podíamos ver a Fidel por televisión, ni podíamos escuchar sus interminables discursos por radio" (1997: 12). Por otra parte, a pesar de este anticastrismo, la vida del autor y del bastión cubano exiliado en Miami no está teñida de desencanto para con Cuba como pueblo y patria. En Cincuenta lecciones de exilio y desexilio, dice estar "Con Cuba. Y contra Cuba", y confiesa que "en mis libros y mis poemas nombro a Cuba obsesivamente", "Cuba, mi espacio. Cuba... mi país" (Pérez Firmat, 2000a: 11-12). Esta forma de ser, de vivir en el pasado, de "remembrear(se)" -merece la pena expresarlo en spanglish — es la manifestación del patriotismo y de la nostalgia. Pero más que patriotismo y nostalgia, es su modo de ser y sentirse cubano. La Pequeña Habanade Miami, sucedáneo de la Habana de Cuba, es el otro pueblo cubano. El autor nos lo recuerda recurriendo a un chiste que se formulaba hace años por la pregunta de saber "por qué Cuba era el país más grande del mundo". Como respuesta, era "porque tenía su territorio en el Caribe, sus gobernantes en Moscú y su población en Miami” (1997: 2). Esta población en Miami, que terminó creando La Pequeña Habana, es también la otra Cuba, donde la cultura cubana se ha trasplantado, donde uno puede "llegar al mundo en un hospital cubano y despedirse del mundo en una funeraria cubana" (1997: 58). Porque el pueblo cubano se extiende allende los mares, la cubanidad inclusive, puede cuestionarse si el cubano de Cuba es más cubano que el cubano de La Pequeña Habana miamense, pese a su anticastrismo. Además, desde la perspectiva ideológica, se puede cuestionar si no fueron el anticastrismo y el exilio los que confortaban esta cubanidad. Fidel Castro era una fijación, una pesadilla y desde luego un tema obsesionante para los cubanos de La Pequeña Habana. Pero desde que el que fue comandante de la Revolución que los obligó a emprender el camino del exilio pasó a ser coma andante y luego otro patrimonio suyo, sería interesante analizar de nuevo La Pequeña Habana desde el prisma político y cultural.

\section{Referencias bibliográficas}

ABASTRADO, C. (1979). Mythes et rituels de l'écriture, Bruxelles, Ed. Complexe. ARENAS, R. (2000). Antes que anochezca: autobiografía, Barcelona, Tusquets. CASTELLANOS, J. (2003). Pioneros de la etnografía a frocubana, Miami, Universal.

CROS, E. (1983). Théorie et Pratique Sociocritiques, Montpellier, C.E.R.S. Université Paul-Valery. FERRER PENAARANDA, C. "Castrismo y anticastrismo en la red: Análisis ideológico de los comentarios a la muerte de Laura Pollán en el periódico digital Público.es", Estudos em Comunicação no 11, mayo de 2012, págs. 125-148. Disponible en http://www.ec.ubi.pt/ec/11/ pdf/EC11-2012Mai-06.pdf. Consultado el 20 de mayo de 2017.

GARCÍA, C. (1998). Soñar en cubano, Madrid, Espasa Calpe.

HALBWACHS, M. (1994). Les cadres sociaux de la mémoire, Paris, Albin Michel.

KANELLOS, N. (Ed.) (2002). En otra voz. Antología de la literatura hispana de los Estados Unidos, Houston, Arte Público Press.

MAURON, C. (1963). Des métaphores obsédantes au mythe personnel. Introduction à la psychocritique, Paris, José Corti.

MERTZ-BAUMGARTNER, B. y PFEIFFER, E. (eds.) (2005). Aves de paso. Autores Latinoamericanos entre exilio y transculturación (1970-2002), Innsbruck, Vervuert.

MOORE, M. "Breve historia del anticastrismo en Miami”. Disponible en http://cartasdesdecuba. com/breve-historia-del-anticastrismo-de-miami/. Consultado el 10 de mayo de 2017. 
OLYMPIA, A. (2005). "Mythe personnel et/ou le mythe de la mondialisation: le cas des deux auteurs francophones grecs du XX ${ }^{\text {ème }}$ siècle", Revista Romana de Studii Culturale, págs. 45-59.

ORTIZ, F. (1991). Estudios Etnosociológicos (Compilación, prólogo y notas de Isaac Barreal Fernández), La Habana, Editorial de Ciencias Sociales.

ORTIZ, F. (1940). "Los factores humanos de la cubanidad”, Revista Bimestre Cubana, 21, págs. 161-186.

PAZ, O. (2007). El laberinto de la soledad, Madrid, Fondo de Cultura Económica.

PÉREZ FIRMAT, G. (2000a). Cincuenta lecciones de exilio y desexilio, Miami, Ediciones Universal. . (2000b). Vidas en vilo. La cultura cubanoamericana, Madrid, Editorial Colibrí. (1999). My own private Cuba. Essays on Cuban Literature and Culture, University of Colorado, Society of Spanish and Spanish-American Studies.

(1997). El año que viene estamos en Cuba, Houston, Arte Público Press.

. (1989). The Cuban Condition: Translation and Identity in Modern Cuban Literature, Cambridge, Cambridge University Press.

STAVANS, I. (1999). La condición hispánica: reflexiones sobre cultura e identidad en los Estados Unidos. México, Fondo de Cultura Económica. 